\title{
A presença britânica na corte siciliana de Frederico II de Hohenstaufen
}

Jonatas Batista Neto

Departamento de História - FFLCH/USP

Durante os 64 anos que transcorreram entre a criação do reino da sicília pelo anti-papa Anacleto II e a sua incorporação pelo Sacro Império Romano, a Sicília foi governada sucessivamente por Rogério II (11301154), Guilherme I (1154-1160), Guilherme II (1160-1189) e Tancredo de Lecce (1189-1194). Sob esses quatro soberanos, a corte de Palermo foi frequentada por elementos das mais variadas origens, dentre os quais destaca-se um certo número de ingleses. A razão da atuação de britânicos na vida política e intelectual siciliana é fácil de ser compreendida: a Inglaterra também tinha sido invadida pelos normandos e, portanto, a presença desses conquistadores nos dois reinos insulares, a despeito da grande distância que os separava, serviu para aproximá-los, permitindo que algumas figuras oferecessem os seus serviços tanto à administração inglesa quanto ao governo palermitano.

Mesmo após a transferência da Coroa siciliana para os monarcas alemães, os ingleses continuaram a frequentar o reino meridional. Dois deles nos interessam particularmente: Isabel, princesa inglesa, irmã de 
Henrique III, que fez a viagem a Palermo para casar-se com Frederico II e Miguel Escoto, astrólogo da corte desse mesmo soberano.

Frederico II de Hohenstaufen é, com toda certeza, uma das mais fascinantes figuras do medioevo. Sua personalidade foi um inquietante problema para os seus contemporâneos - que o chamaram de Stupor Mundi e, às vezes, o consideraram como a encarnação do Anticristo para os filósofos e historiadores modernos, como, por ex., Nietzsche, que viu nele um Raetselmensch, comparável a Alcibíades, Júlio César e Leonardo da Vinci, e Jacob Burckhardt, que escreveu sobre ele uma passagem célebre na sua grande e famosa obra sobre o Renascimento italiano:

\begin{abstract}
"Este príncipe que, na vizinhança dos sarracenos, crescera no meio de traições e perigos de toda espécie, habituara-se, cedo, a julgar e a tratar as coisas de uma maneira bem objetiva: ele é o primeiro homem moderno coroado. Acrescente-se a isso o conhecimento exato e aprofundado do interior dos estados sarracenos e de sua administração, e essa guerra com os papas na qual os dois partidos punham em jogo a sua existência, e que forçava a fazer apelo a todos os meios e a todos os recursos imagináveis (1)".
\end{abstract}

Herdeiro dos reis normandos, dos quais parecem derivar alguns de seus costumes, como o harém, o gosto pelos banhos frequentes, o interesse pelos animais, e as suas atitudes de déspota oriental, e que, aliás, the valeram o título de "sultão batizado", Frederico surpreendeu o seu tempo pela amplitude que deu às tendências que já se manifestavam na Corte siciliana desde a época de Rogério II. A enorme curiosidade científica, ele associa o gosto pelas soluções precisas e definitivas, inculcadas pelos matemáticos de formação árabe, no meio dos quais cresceu em Palermo. Além disso, ele conserva o cenário luxuoso que tinha sido sempre o pano de fundo da dinastia Hauteville, vivendo cercado de poetas que, como Jacopo da Lentini e Giacomino Pugliese, foram, frequentemente, funcionários da Corte (2). Rodeado por artistas e cientistas de diversas origens e sempre em contacto com intelectuais judeus e maometanos, o próprio Frederico aventurou-se no terreno da poesia e deixou, sobre a sua grande paixão, a caça com falcão, um tratado denominado De Arte Venandi Cum Avibus. O seu gosto pelas atividades culturais e o seu interesse em protegê-las se manifesta espetacularmente em 1224, quando, em Siracusa, ele anuncia que criara uma nova escola de nível internacional. O reino, que já contava com recursos de medicina minis-

(1) - Burckardt, J. La Civilisation de la Renaissance en Italie, (trad. francesa) . Paris, 1958, I, p. 6 .

(2) - Cf. Labande, E. R. L'Italie de la Renaissance. Paris, 1954, p. 62. 
trados em Salerno, passava, agora, a ter um Studium Universale, instalado em Nápoles, para o qual foram atraídos professores estrangeiros com promessas de bons salários. Os súditos sicilianos foram proibidos, pelo Imperador, de estudar fora do reino, a fim de que não fossem contaminados por idéias guelfas (3).

Não foi apenas a sua vasta curiosidade intelectual que determinou a sua fama. Se os seus contemporâneos o respeitaram atemorizados, isso se deve também ao interesse que ele sempre teve pelo governo, pelo aperfeiçoamento das engrenagens administrativas e pelos detalhes da vida econômica e à impiedosa energia que costumava usar para reprimir qualquer desafio à sua autoridade. Mais do que tudo isso, todavia, parece ter pesado na elaboração do seu mito, a tenaz resistência que sempre ofereceu às pretensões romanas de controlar o Império. Assim como o reinado de seu avô Frederico Barbarruiva, a sua época é de luta incansável entre as pretensões de pleno poder da Igreja e os esforços de fazer valer concretamente as concepções imperiais.

Salimbene de Adam, que o conheceu, apresenta Frederico II como um soberano em cuja personalidade associam-se defeitos graves e qualidades atraentes. Segundo o cronista, se ele tivesse amado Deus e a Igreja, teria sido um grande líder cristão, bastante superior a qualquer outro de seu século. $\mathrm{Na}$ verdade, Salimbene não percebe que o fascínio do soberano vem mais de tudo o que o faz suspeito ao seu tempo do que das virtudes padrões que se costumava encontrar num rei mais convencional. A passagem da crônica em questão, apesar de muito conhecida, merece ser reproduzida, mesmo porque, nela, há alusões às experiências científicas de Frederico:

"Era um homem astucioso, dissimulado, cúpido, luxurioso, malicioso, irritável. E era, ao mesmo tempo, um homem cheio de valor, quando ele queria fazer alarde de suas bondades ou amabilidades, benevolente, encantador, delicioso, ativo; ele sabia ler, escrever, cantar e compor cantilenas e canções: ele era um homem belo e bem proporcionado, mas de estatura média. Eu o vi e o amei imediatamente. Ele sabia igualmente grande número de línguas diferentes. Em resumo, para terminar, eu diria que se tivesse sido bom católico, tivesse amado a Deus e à Igreja e à sua alma, teria havido, no mundo, bem poucos soberanos à sua altura (...) Ele queria saber pela exeperiência, que espécie de língua e de idioma teriam as crianças se crescessem sem falar com ninguém. E ele ordenou,

(3) - Cf. Schipa, M. Italy and Sicily under Frederick II, in The Cambridge Medieval History, VI, p. 143. 
às crianças e às nutrizes, que dessem leite aos recém-nascidos, que os fizessem mamar no seio, que os banhassem e os limpassem mas que não os mimassem de forma alguma nem lhes falassem; porque ele queria saber se eles falariam hebraico, primeira língua a surgir, ou o grego ou o latim ou o árabe, ou então a língua de seus pais, daqueles de quem eles tinham nascido. Mas ele se esforçava em vão porque as crianças ou os recém-nascidos morriam todos. Ele deu um excelente e copioso almoço para dois homens, mandou um dormir e o outro caçar e, a noite seguinte, fez com que lhes arrancassem as entranhas na sua presença, porque ele queria saber quem tinha feito melhor a digestão... (4).

Uma figura tão original iria logo transformar-se em lenda. Na tradição popular, ele foi o núcleo da Kaisersage germânica, segundo a qual o soberano, adormecido numa caverna do Etna, espera o dia em que soará a hora do seu retorno para, acompanhado por seus cavaleiros, reiniciar a obra de restauração do Império e de libertação dos oprimidos. Personagem cosmopolita, Frederico deixou marca em autores árabes, judeus e gregos. O tradutor Jacob Anatoli louva o soberano, a quem chama de "amigo da sabedoria e de seus devotados", e espera que o Messias possa vir durante o seu reinado. Poetas gregos, da Itália meridional, como João de Otranto e Jorge de Gallipoli, fazem o seu elogio e Teodoro Láscaris 1amenta a sua morte numa oração fúnebre. No Ocidente, o imperador foi celebrado por trovadores provençais e Minnesinger alemães (5).

Das três esposas que Frederico teve, uma, a princesa Isabel, irmã de Henrique III, era inglesa. Essa escolha foi feita graças à influência do papa Gregório IX. Logo após o encontro do imperador com o papa, em Rieti, no ano de 1234, Piero della Vigna foi despachado para Londres, a fim de negociar o casamento. Esse passo teve um duplo sentido: não só ele foi importante em termos de política externa como também teve o seu significado no que diz respeito ao equilíbrio de forças dentro da própria Germânia. Até esse momento, Frederico tinha manifestado simpatia pela França e vinha-se opondo à Inglaterra que apreciava as pretensões guelfas. $O$ casamento com Isabel foi o primeiro passo no sentido de por fim à famosa hostilidade que dividia o reino alemão e o Império, ou seja, o conflito entre os membros da casa dos Welf e os partidários da família reinante, os Hohenstaufen.

Mateus Paris, que costumava tratar minunciosamente de aspectos relacionados com a vida íntima dos poderosos, nos informa que, logo

(4) - In:Monumenta Germaniae Historica, XXXII, p. 348, apud de la Roncière, C. M. et alii, L'Europe au Moyen Age. Paris, 1969, II, p. 45.

(5) - Cf. Haskins, C. Studies in Medieval Culture. N. York, 1965, p. 125. 
após ter o rei inglês dado o seu consentimento para que o enlace tivesse lugar, os enviados imperiais pediram licença para ver a princesa e Isabel, nessa altura uma jovem de apenas 21 anos de idade, foi trazida da Torre de Londres, onde residia, para o palácio de Westminster, que tinha sido o local das negociações. Os emissários contemplaram-na longamente e, considerando-a digna de partilhar o leito imperial, colocaram-lhe num dos dedos, em nome de Frederico, o anel do compromisso, e saudaram-na como imperatriz do Império Romano (6).

O mesmo cronista se compraz em enumerar as suas jóias, as várias peças do seu vestuário, colchas de seda, as almofadas e até as panelas de cozinha, que eram de prata pura e que, a todos, pareceram supérfluas. Depois, segue-se a viagem por terra, a travessia do mar e a chegada a Colônia, cuja população the preparou uma festiva recepção. Milhares de pessoas se reuniram, transportando flores, ramos de palmeira e instrumentos musicais. Utilizando cavalos espanhóis, alguns cavaleiros fizeram, com as suas lanças, uma demonstração guerreira apropriada para cerimônias nupciais. Certos clérigos executaram novas peças musicais dentro de navios que, arrastados por cavalos cobertos por grandes mantos de seda, "navegavam" em terra firme. Por sua vez, as curiosas matronas aglomeradas nos balcões, cantaram louvores à beleza da imperatriz quando esta, a seu pedido, retirou o chapéu e o véu, mostrando inteiramente a face. Todas esses manifestações foram realizadas em maio. Depois, até meados de julho, a princesa esperou que Frederico chegasse. Em 15 de julho de 1235, com grande pompa, o casamento foi realizado em Worms (7).

Causou espanto - e, naturalmente, provocou muito comentário o fato de o imperador não ter consumado o casamento na primeira noite mas ter esperado a hora do dia seguinte que os astrólogos indicaram como a mais propícia para a procriação. A partir desse momento, dizendo que ela já se encontrava grávida, Frederico entregou a nova imperatriz aos cuidados de eunucos sarracenos. Essa mesma informação foi logo enviada, numa carta, ao soberano inglês. Ao contrário dos seus antecessores normandos, o "sultão batizado" encarava suas esposas simplesmente como mães de seus herdeiros legítimos e sucessores. Elas não tiveram nenhum papel de relevo como imperatrizes. No passado, sempre que faziam doações à Igreja, os monarcas alemães incluíam o nome da esposa nas cartas correspondentes; temos, nesses documentos, vários exemplos de doaçães conjuntas feitas pelo casal real; neles aparecem os nomes de Frederico I e

(6) - Cf. Kantorowicz, E. Frederick the Second, 1194-1250, trad. inglesa, N. York, 1957, pp. 406-7.

(7) - idem, p. 407 
Beatriz, Henrique VI e Constança, etc. Na época do neto de Barbarruiva, as mulheres são deixadas na sombra. Com a única exceção de uns poucos documentos relacionados com os acordos de casamento, os registros de Frederico II não contém alusões às suas consortes. Essa atitude se refletiu também na designação reservada a seus filhos, para os quais usou-se apenas a expressão Divi Augusti Imperatoris Filius.

Anos depois do casamento, Henrique III da Inglaterra queixou-se do fato de que sua irmã nunca usara a coroa imperial em público. Os inimigos dos Hohenstaufen acusaram o imperador de ter aprisionado suas esposas no "labirinto de sua Gomorra", tornando-as quase invisíveis e estranhas aos seus próprios filhos. Kantorowicz diz que essa acusação correspondia bem à verdade, uma vez que nenhuma mulher conseguiu manter uma posição destacada ao lado de Frederico. Todas as suas esposas morreram poucos anos após o casamento e, ao que parece, suas amantes tiveram o mesmo destino (8). Ou, nas palavras do citado biógrafo:

"In the rarified atmosphere of these brilliant heights no human being but himself could thrive: none even of his friends could hold out for long; no woman could have breathed there. Hence, the English Isabella, surrounded by her imperial household and dignities, watched by eunuchs, disappeared forthwith into the 'harem' " (9).

Se Isabel não chegou a ter nenhum papel de relevo na Corte, o mesmo não aconteceu com o outro elemento de origem britânica que se envolveu com o Hohenstaufen em questão: Miguel Escoto foi uma das figuras mais importantes - se não a mais imporatnte - do círculo de letrados da corte e a sua atuação foi decisiva até mesmo na formação intelectual do soberano.

Escoto foi um dos vários latinos ligados a Frederico. Antes de menciná-los e de tratar do sábio escocês, convém lembrar que o próprio imperador foi um autor latino. Grande conhecedor do De Animalibus de Aristóteles, o monarca siciliano deixou uma obra sobre a falcoaria, intitulada De Arte Venandi Cum Avibus. Acredita-se que os conhecimentos de latim e de estilo latino demonstrado nesse tratado sejam o resultado da instrução ministrada por seu mestre Willelmus Francisius. Todavia, - autor dessa suposição, o historiador C. H. Haskins, adverte que esse texto não está isento de falhas: além de o tratamento dado ao assunto ser trivial, o estilo é simples, pouco adornado, com algumas desconexões e repetições; mais ainda, manifesta-se claramente, no texto, a influência do
(8) - ibidem.
(9) - idem, p. 408. 
vernáculo, para cujos termos técnicos ele tem dificuldade de achar equivalentes latinos (10).

Segundo Nicolau de Iamsilla, antes da ascensão de Frederico, havia poucos - ou mesmo nenhum - erudito no reino meridional. Foi ele, portanto, segundo o mesmo autor, quem se preocupou em atrair, para $\mathrm{Pa}$ lermo, mestres de todas as partes da terra. Seja ou não verdade essa declaração, o certo é que, sob o filho de Henrique VI, encontramos um bom número de escritores latinos na Sicília, dentre os quais merecem destaque Teodoro de Antióquia, filósofo e secretário da Corte, que sucedeu a Miguel Escoto e atuou de 1238 até 1250, Piero della Vigna, juiz da Magna Cúria - de 1225 a 1247 -, logoteta e protonotário, Terrisio di Atina, Petrus de Ebulo, Adam de Cremona, Leonardo de Pisa, Henrique de Avranches, Ricardo de Venosa, Orfino de Lodi e Giordano Ruffo da Calabria (11).

E provável que o encontro de Miguel Escoto com Frederico tenha ocorrido por ocasião da visita deste a Bolonha, em 1227, após a sua coroação. O que se sabe da vida desse cientista escocês é bem pouco. Ele começou a sua carreira em Toledo, onde traduziu um tratado de Geometria de Alpetragius, por volta de 1217. Em 1220, ele passou por Bolonha e, depois, esteve algum tempo em contacto com a Cúria papal, que o recomendou ao arcebispo de Cantuária. Esses contactos devem ter facilitado o encontro de 1227, que ocorreu na mesma ocasião em que o imperador fez as pazes com o matemático Leonardo de Pisa.

Se a sua vida é pouco conhecida, sabemos de várias lendas que nasceram do fato de Miguel Escoto além de tradutor, filósofo e matemático, ter sido áugure e astrólogo. Os contemporâneos, que temiam não só o intelectual como também o seu protetor, chamaram-no de "segundo Apo10", por causa dos seus dons divinatórios. Dizia-se também que ele tinha predito o lugar da morte de Frederico II e que, consciente de que a sua própria morte seria provocada pela queda de uma pedra de 2 onças de peso, passara a usar, sempre, um capacete de ferro; tendo retirado essa proteção numa igreja, por ocasião da elevação da hóstia, foi fulminado por um fatídico bloco que se desprendeu do teto. Segundo a tradição italiana, ele teria morrido na Itália; outros relatos dizem que morreu na sua terra natal e foi enterrado em Holme Cultram em Cumberland ou na abadia Melrose. Nos dois últimos séculos da Idade Média e na Idade Moderna, lendas foram-se formando em torno do seu nome: segundo alguns, ele costumava brindar os seus amigos com pratos magicamente surrupiados às cozinhas reais da França e da Espanha; segundo ou-

(10) - op. cit., p. 127.

(11) - idem, pp. 129-30. 
tros, numa ocasião em que fizera parte de uma embaixada enviada ao soberano francês, o trote do seu cavalo fez com que o sino de Notre-Dame batesse e as torres do palácio desabassem. Outros poderes e proezas aparecem no poema de Folengo, intitulado Merlin Coccaius, que foi redigido na última década do século XVI. Na época romântica, ele foi ressuscitado por Walter Scott no Lay of the Last Minstrel, cujo episódio mais notável é justamente a abertura da tumba do feiticeiro (12). Essa reputação de mágico, cujos ecos ressoaram até o século XIX foi estabelecida bem cedo. Tanto em Dante como em Boccaccio, ele aparece dessa forma. O primeiro autor o colocou no Inferno, no quarto compartimento do oitavo círculo, entre os adivinhos Tirésias, Aronte, Manto, Eurípilo e Asdente. Todos estes, bem como Escoto, caminham em procissão, trazendo a cabeça virada para trás, de maneira que o pranto escorre pelas costas, até as nádegas. A ambição de penetrar nos segredos do futuro é a causa desse castigo que, agora, fá-los olhar sempre para o passado. Em três versos do canto XX, Dante retrata o sábio escocês como homem franzino e perito nas fraudes mágicas:

"Quell'altro che ne' fianchi è cosí poco,

Michele Scotto fu, che veramente

delle magiche frode seppe il gioco" (13).

Quanto a Boccaccio, ele o cita na novela em que o médico Simão da Villa é enganado pelos pintores florentinos Bruno e Buffalmaco. O primeiro diz, ao estúpido bolonhês, que Miguel Escoto deixara, em Florença, dois discípulos, nigromantes, que tinham fundado uma especie de sociedade secreta onde os membros se banqueteavam, num ambiente requintado, recebiam a visita de magníficas mulheres provenientes do mundo inteiro (14).

Se as fantasias abundam, os fatos, historicamente comprovados da vida de Escoto são em número reduzido. Antes de iniciar a sua carreira em Toledo, onde aprendeu o árabe, ele parece ter estudado em Oxford e Paris; foi ordenado, deteve vários benefícios na Itália, e recusou o cargo de arcebispo de Cashel, na Irlanda. Após o seu encontro com Frederico II, dedicou-se, juntamente com Hermannus Alemannus, ao estudo e à tradução de Aristóteles e de seus comentadores.

Costuma-se atribuir a Miguel Escoto um número de obras bem maior do que ele, na verdade, pôde produzir. É certo, todavia, que ele traduziu o De Caelo e o De Anima de Aristóteles com os comentários de Aver-

(12) - Cf. Encyclopaedia Britannica ("Michael Scot").

(13) - 115-117.

(14) - Il Decamerone, VIII, 9. 
roes e também os escritos zoológicos do filósofo grego que Avicena tinha agrupado sob o título de Liber animalium: Historiae animalium, De partibus animalium. Assim como a maioria dos seus trabalhos, essa obra foi dedicada ao imperador. Graças a ele, pela primeira vez, a zoologia aristotélica foi introduzida no Ocidente. Uma reprodução da cópia do Liber animalium que pertenceu ao soberano foi feita por Henrique de Colônia em 1232 e Kantorowicz acredita que ela possa ter sido usada por Alberto Magno (15). Também the foram atribuídas - ao que parece erroneamente - traduções da Física e da Metafísica e alguns obscuros tratados filosóficos: as Questiones de Nicolau o Peripatético e uma Filosofia Sistemática (16).

Em 1227, segundo Mampe (17), Frederico endereçou a Miguel Escoto uma série de perguntas que parecem por em dúvida as próprias bases da fé católica. O sábio escocês relata, na sua Enciclopédia, como foi que o imperador recorreu a ele:

"Uma vez, quando Frederico, Imperador de Roma, o eternamente ilustre, tinha longamente refletido de acordo com uma ordem que ele mesmo tinha estabelecido sobre as diferenças de toda a terra, sobre quais são elas e como elas aparecem sobre, acima, dentro e sob a terra, ele as enviou secretamente para mim, Miguel Escoto, - mais fiel de seus astrólogos, e pôs um número de questões diante de mim, secretamente, como the agradara fazer, sobre os fundamentos da terra $\mathrm{e}$ as maravilhas dela, assim dizendo:

"Meu caríssimo Mestre. Temos, frequentemente, e de diversas maneiras, ouvido questão e resposta de um e de outro sobre os corpos celestes, sobre o sol e a lua e as estrelas fixas, sobre os elementos, a alma do mundo, sobre povos pagãos e cristãos e outras coisas criadas que existem sobre e dentro da terra, tais como plantas e metais. Contudo, nós nada ouvimos daqueles segredos que deliciam a mente que está ligada à sabedoria: sobre o Paraíso, o Purgatório, o Inferno, os fundamentos e as maravilhas do mundo. Assim, nós lhe pedimos, pelo seu amor da sabedoria e sua lealdade a nosso trono, que nos explique a estrutura da terra:

1. Como está fixa a Terra sobre o abismo do espaço?

2. E como está esse abismo fixo sob a Terra?

3. Há algo mais que suporta a Terra além do ar e da água?

4. Ou a Terra permanece fixa por si mesma?

(15) - op. cit., p. 340 .

(16) - ibidem.

(17) - cit. por E. Kantorowicz, op. cit., p. 350. 
5. Ou ela descansa sobre os céus que estão abaixo dela?

6. E quantos céus há?

7. Quem os dirige?

8. Qual é a distância de um céu a outro de acordo com as nossas medidas?

9. Quem habita os céus?

10. E, se há muitos céus, o que há depois do último?

11. Quanto um céu é maior que outro?

12. Em que céu está a substância de Deus, que está na Sua divina majestade, e de que maneira Ele está sentado sobre o trono do céu?

13. De que maneira Ele é acompanhado pelos anjos e santos?

14. E o que os anjos e os santos fazem ininterruptamente na presença de Deus?

15. Conta-nos também: quantos Infernos há?

16. Quais são os espíritos que habitam lá?

17. E por que nomes são chamados?

18. Onde estão o Inferno e o Purgatório?

19. E o Paraíso celeste? Sob a Terra? Sobre a Terra? Dentro da Terra?

20. Qual é a diferença entre as almas que vão para o Inferno e os espíritos que caem do Céu? $\mathrm{E}$ quantos tormentos há no Inferno?

21. E uma alma conhece a outra na vida futura? E pode uma alma retornar a esta vida para falar ou mostrar-se a alguém?

22. E ainda: se, quando uma alma de um homem vivo passa para a outra vida, nada pode dar-lhe o poder de retornar, nem o amor, nem mesmo o ódio, como se nada jamais houvesse ocorrido? Ou a alma não se preocupa com nada que foi deixado para trás, seja ela abençoada ou condenada (18)?"

Segundo Kantorowicz, essas questões refletem a preocupação de Frederico II com a "aparência" do outro mundo. Seu interesse, neste caso, é idêntico ao que ele costumava manifestar com relação aos diversos reinos muçulmanos (19). O reino de Deus era, para ele, apenas mais um objeto de conhecimento e de delícia da mente.

Além disso, o imperador foi frequentemente instruído, por Miguel Escoto, sobre as diferentes propriedades dos minerais e metais. Em certos manuscritos medievais, o sábio britânico aparece mesmo como autor de obras sobre alquimia. Isso não é improvável porque um breve resumo da 
doutrina alquímica realmente aparece num capítulo de uma de suas obras autênticas sobre astrologia, escrita entre 1227 e 1235; essa passagem é, aliás, um dos primeiros exemplos desse assunto redigidos em latim.

No que diz respeito aos outros tratados alquímicos atribuídos a Escoto, impõe-se uma certa cautela, tendo em vista o grande número de obras que estão falsamente ligadas ao seu nome. Uma delas, a Alquimia, chegou a nós em dois manuscritos, que, além de ilustrar os processos utilizados no século XIII, lançam um pouco de luz sobre as fontes dos trabalhos científicos da época. Neles não aparece nem a tradução obediente das grandes obras árabes tradicionais nem as experiências independentes de elementos ocidentais agindo num certo isolamento. $O$ que surge nesses textos é a atividade de cientistas latinos que, no entanto, estão claramente em estreito contacto com pesquisadores judeus e sarracenos. Eles observam o mestre Jacob, o judeu, em Sarzana; citam experiências específicas, ou documenta, de sarracenos da África, Túnis, Maiorca e Aleppo; e notam o acordo entre as idéias de Barac e Boala e Miguel Escoto. Este último, como já vimos, esteve em Toledo e, se o prefácio da sua Alquimia merece crédito, o tratado foi dedicado a um funcionário sarraceno de Túnis. Há, ainda, na mesma passagem, referência aos contactos do escocês com alquimistas de outras terras (20). Tendo vivido na Espanha e na Sicília e mantido essas conexões, o astrólogo Miguel Escoto é, bem provavelmente, o autor da obra em questão. Os princípios e as práticas da alquimia the eram familiares; seus contactos com judeus e maometanos cultos não se limitavam nem à Itália nem à corte de Frederico II; e seu conhecimento de idiomas - especialmente o hebraico e o árabe - foi atestado até mesmo pelo papa Gregório IX (21).

Referências encontradas tanto em Escoto como em outros autores medievais levam-nos à conclusão de que os judeus tiveram enorme influência na formação intelectual de Miguel Escoto. Por ex., um certo A.buteus - Levita teria auxiliado o sábio em questão, em Toledo, no ano de 1217, quando este trabalhava na versão latina do tratado sobre a esfera de AlBitrogi. Além disso Roger Bacon afirma que foi um judeu, chamado André - talvez o próprio Abuteus - , quem realizou a maior parte das traduções de Escoto. Haskins (22) acredita que esse linguista possa ser identificado ao Mestre André, que foi feito cônego de Palência, a despeito da sua origem, e que é louvado pelo papa Honório III por sua grande cultura, não só nas 7 Artes Liberais como também nas seguintes línguas: hebraico, caldeu, árabe e latim.

(20) - Cf. C. Haskins, op. cit., p. 157.

(21) - idem, p. 158.

(22) - idem, p. 159. 
Os conhecimentos alquímicos de Escoto foram úteis ao imperador Frederico, que se interessou também pelas propriedades das diversas ervas e drogas e chegou a enviar mensageiros à Noruega a fim de investigar sobre as propriedades paralizantes de uma certa fonte (23). Aguilhoado por uma enorme curiosidade, 0 soberano recorreu sempre à grande obra do referido autor, a qual era não somente uma enciclopédia astronômica e astrológica como também um compêndio de ciências secretas. Escoto se baseou, em muitos pontos, em fontes perigosas, como o Liber perditionis animae et corporis, por ex., que continha os nomes, as habitações e os poderes dos demônios, e o Liber Auguriorum, que fora condenado pela Igreja (24) .

Encontramos, também, nos seus escritos, as velhas preocupações com os números e o seu simbolismo. O sete, por ex., governa o mundo porque 7 é o número dos planetas, dos metais, das artes, das cores, dos tons e dos cheiros. Também da música trata Escoto, expondo, de forma sumária tanto as difundidas doutrinas de Boécio quanto as recentes teorias de Guido de Arezzo. Numa outra passagem, ele se dedica à contagem do tempo, tratando do calendário. O profundo conhecimento astronômico e astrológico que demonstra em seus tratados, Escoto deve ao Almagesto e a Al-Fargani, bem como aos antigos teóricos - Nigidius, Fulgentius, Plinius, Hyginus, Martianus Capella e Aratus - incluídos na obscura Scholia de Germanicus. No que diz respeito à astrologia num sentido restrito, seus conhecimentos procedem dos árabes, mormente de Albumazar, em cuja obra se reuniram informações provenientes de Hermes, de Dorotheus, do babilónico Teucer e de estudiosos persas e indianos (25).

Kantorowicz diz que, em resumo, na corte imperial, todas as superstições do Baixo-Império romano, que tinha sido profundamente penetrado pela maré das influências orientais, retornaram novamente à vida, assim como o ensinamento gnóstico despertou os heréticos do mesmo período (26), especialmente na Lombardia e na França meridional. De tal modo Frederico se interessou por essa sabedoria ressuscitada que, num certo momento, Escoto dirigiu-se a ele da seguinte maneira:

"O afortunado Imperador! Eu realmente acredito que, se algum homem pudesse escapar à morte graças ao seu conhecimento, tu serias esse homem... (27)"

(23) - E. Kantorowicz, op. cit., p. 354.

(24) - idem, p. 355 .

(25) - ibidem.

(26) - ibidem.

(27) - ibidem. 
O citado biógrafo acredita que a cultura do soberano deve ter sido extraordinária. Seus conhecimentos abrangiam o campo das línguas, da jurisprudência, da literatura antiga, da escolástica, da ciência, etc. Preocupado também com a solução de problemas práticos, Frederico recorreu a Escoto no sentido de dominar a ciência da fisionomia humana. A seu pedido, o erudito escocês compilou, com base em fontes helenísticas e árabes, um ensaio sobre a aparência das pessoas. $\mathrm{Na}$ dedicatória, ele assegura que, com esse tratado, um governante poderia conhecer os vícios e as virtudes do seu círculo de amizades sem qualquer risco de engano (28).

A Miguel Escoto atribuem-se diversas obras e traduçōes. Entre estas estão De Animalibus, De Anima, De Coelo e, provavelmente, a Física e a Metafísica de Aristóteles, bem como a De Sphaera de Al-Bitrogi. Quanto às suas obras, a maioria delas trata de astrologia, alquimia e ciências ocultas. As principais são: Super auctorem spherae (impressa em Bolonha em 1495 e em Veneza em 1631), De Sole et Luna (impressa em Estrasburgo em 1622, no Theatrum Chimicum); De Chiromantia (opúsculo frequentemente publicado no século XV); De physiognomia et de hominis procreatione (18 edições entre 1477-1660). De todas essas, duas - a Physiognomia e a Super auctorem spherae - contêm passagem na qual se diz claramente terem sido empreendidas a pedido do imperador Frederico (29) .

Se na época dos soberanos normandos o reino da Sicília foi bastante frequentado por ingleses, já no reinado do grande Hohenstaufen percebemos um declínio da participação britânica da ilha. Miguel Escoto é uma figura extraordinária e interessantíssima, não há dúvida. Mas não só ele é um elemento isolado - a princesa Isabel foi apenas uma consorte imperial, que não deixou marca mais visível na História da ilha - como também a sua presença em Palermo não implicou em conexões especiais entre os dois reinos de que estamos tratando. Mesmo porque Miguel Escoto era escocês e não inglês. Percebemos, assim, que os vínculos que ligavam a Inglaterra à Sicília no século XII afrouxam-se no XIII e tendem a desaparecer. Após a morte de Frederico em 1250, o reino mediterrânico passa para a esfera da influência francesa. Com as vitórias de Benevento (1266) e Tagliacozzo (1268), Carlos de Anjou se apossa dele. Catorze anos depois, em 1282, os franceses são expulsos da Sicília, que se torna parte do reino de Aragão. Esses grandes modificações políticas são a causa principal da interrupção dos contactos que estudamos neste artigo. De tal forma o reino siciliano se afasta das influências setentrionais, passando a fazer parte de um quadro puramente mediterrânico, que a pre-

(28) - idem, p. 356.

(29) - V. "Michael Scot" in Encyclopaedia Britanica. 
$-46-$

sença britânica na ilha e no sul da península não é mais perceptivel no fim do século A grande época da atuação inglesa na Sicília estava encerrada. 